\title{
Foreign Students, Libraries, and Culture
}

\section{Mary Alice Ball and Molly Mahony}

The number of foreign students in the library is increasing, and, with it, librarians' commitment to improve service to this portion of the academic community. This paper discusses two approaches to place the foreign student and the academic library in a cultural context: bibliographic instruction and staff development.

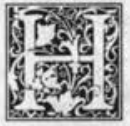

ow often do you cringe when a foreign student approaches the reference desk, anticipating at best an awkward, at worst a failed attempt at communication? If your college or university is typical, the number of foreign students enrolled has increased steadily in the past decade. As the cost of a college education in the United States has risen beyond the means of many American families, students who, a decade ago, would have attended four-year colleges are opting for community colleges, technical schools, or the armed forces. Academic administrators are compensating for this decline by recruiting new students from overseas. There are a number of reasons foreign students are attractive candidates for admission: often they pay full tuition; they tend to be among the brightest their countries have to offer; and their later success in their home countries enhances the image of the university.

Universities have had programs and international centers for foreign students for many years, and libraries may even have offered special classes for them, but only recently has competition for these stu- dents increased among institutions. ${ }^{2} \mathrm{Li}$ braries have been considered by many to be the center of the university. If this is the case, they have a responsibility to help the university recruit new students by assessing services currently offered to foreign students, redesigning them or creating new ones. Even if it is not the case, librarians should take advantage of an excellent opportunity to expand services to an often neglected segment of the university community.

Much has been written about bibliographic instruction for foreign students. Some have written of specific teaching strategies, and others have concentrated on cultural or communication problems. ${ }^{3}$ Terry Ann Mood has suggested staff development programs as a way to increase sensitivity to the problems encountered by foreign students, and thus, to improve service to them. ${ }^{4}$ This article describes efforts on the part of the undergraduate library at the University of Michigan to respond to these ideas in concrete ways. Classes designed for foreign students have been taught for the past three years, and the first staff development workshop

Mary Alice Ball and Molly Mahony were both Research Library Residents at the University of Michigan Undergraduate Library, Ann Arbor, Michigan 48103. Ms. Ball is now at NOTIS, Northwestern University Library, Evanston Illinois 60201. Molly Mahony is at the Library, Keene State College, Keene, New Hampshire 03431. 
was held in summer 1985. Certainly not all academic institutions have the resources of the University of Michigan, but this should not keep them from experimenting with some or all of our programs and adapting them to suit local conditions.

\section{LIBRARIES REFLECT CULTURE}

Sally G. Wayman stresses the importance of recognizing the differences between overseas libraries and those in the United States and how different expectations can affect a student's use of the library. ${ }^{5} \mathrm{~A}$ glance at the International Handbook of Contemporary Developments in Librarianship shows exactly how resources can vary from one country to another. ${ }^{6}$ In Saudi Arabia, university libraries have two identical facilities with duplicate collections, one for men and the other for women. ${ }^{7}$ Books in most Third World countries are valuable resources and their use is discouraged so they will not be damaged. Most foreign libraries have closed stacks, and material is paged by clerks. In all too many countries the librarian is not considered a professional and when a library administrator is designated he is almost without exception a male professor. Public service is a uniquely Western concept with which most foreign students are unfamiliar.

Most students come to the United States fully understanding that they must adapt to our institutions, and they are eager to do so. Western universities are distinguished by their emphasis on independent research; students who do not acquire this skill can never fully profit from an education in the United States. It is our responsibility then to define the library setting for these students, to let them know what services are available, and to teach them how to use the basic research tools.

\section{BUILDING A RELATIONSHIP WITH YOUR CLIENTELE}

Identifying students for these specialized bibliographic instruction classes may or may not be difficult, depending on the institution. Often foreign students congregate at an international center,
English-language school, or the office of the foreign student advisor. The campus newspaper and bulletin boards can be used to advertise the program. Professors themselves may contact the library about orientation sessions for their students. In the fall of 1985, the University of Michigan Undergraduate Library was invited by the International Center to participate in orientation sessions for visiting scholars from the People's Republic of China. In the United States only for limited periods, these professors are an often ignored part of the foreign community on campus.

It may be difficult for foreign students to overcome linguistic and social insecurities and approach a stranger at the reference desk. The bibliographic instruction session provides the librarian with an opportunity to become a friendly face in this land of unfamiliar ones. If we show foreign students that we do not expect perfect English from them and that we value the considerable effort they are making by studying in the United States, they will respond by opening up and trusting us to help them. Sometimes the results may be more than we expected, as students return at a later date to request help organizing or researching a term paper. In our experience, students who heard of us through friends have arrived with a request to edit a dissertation proposal or demonstrate the use of a microcomputer. Once a librarian is recognized as a person who is able and willing to help, foreign students will not hesitate to ask for assistance. A positive or negative experience with one librarian may influence a student's perception of an entire staff.

How does a librarian begin to build this relationship? Often by doing little more than beginning a class by asking students' names and home countries, writing down and memorizing those names, and using them during and after class, the first steps are taken. Foreign students will want to address you appropriately, but may be confused by American informality. To avoid any misunderstanding let them know what you want to be called. You may also want to tell them how you became interested in working with foreign students.

When developing goals and objectives 
for the bibliographic instruction class, the librarian should consider what is important besides teaching cultural knowledge or practical research skills. One objective of most public service librarians is to build a positive relationship with the students. This may be difficult to do in a fifty- or sixty-minute class period, but is necessary if we expect them to come back in the future for help. Usually class size should be kept to ten to fifteen students so the librarian can respond to individual needs. By being flexible when teaching and allowing enough time for the lesson, most objectives can be achieved.

Teaching aids are especially important when dealing with foreign students because they will not be able to absorb a spoken lesson as well as native speakers of English. They will probably read English much better than they speak it or comprehend it aurally, so using the blackboard or handouts to emphasize important points is recommended. Handouts that duplicate the lesson shown on overhead transparencies can be used by students to take notes and can be reviewed by them later, reinforcing the classroom lecture.

Often we fall into the trap of assuming a basic level of knowledge. We should be particularly wary of assuming a basic level of knowledge. Average college students are confused by words like citation and bibliographic. How much more baffling for a foreign student! It is useful to develop a glossary of library terminology the students can refer to during class.

Foreign students also need to be informed of the services available in the library and exactly what they comprise. Services such as reserves, interlibrary loan, database searching, and term paper consultation should be explained briefly. They may not exist in the students' home countries and without prior experience it will be easy for them to overlook these integral parts of American college libraries.

\section{TEACHING RESEARCH METHODS}

In many overseas universities, resources are so limited that it is almost impossible to do independent research, be- cause the necessary books and journals are not available. The teacher, not the library, is the repository of knowledge, and critical analysis is a function of the teacher, not the student. It is the student's responsibility to listen to and absorb the lecture without questioning its validity.

Coming from such a highly structured environment, students may not know where or how to begin a research project. A general discussion of the relative merits of books and journals will help students learn to assess the types of material most appropriate for their work. Foreign students may find encyclopedia or other reference sources especially valuable because they present important vocabulary and information with clarity and conciseness.

The core of any bibliographic instruction class for foreign students should be an explanation of the card catalog and periodical indexes, with subsequent practice in how to use them. It is necessary to explain the classification system in concrete terms, perhaps even supplying call numbers for the students to arrange. The link between the call number and the physical item must be made clear.

Detailed transparencies of catalog cards with their components clearly indicated are another essential tool easily forgotten by librarians. With so much written on a card, students need help interpreting important information.

Students are often unaware of the variety of periodical indexes available. This is particularly true of foreign students, so it is important to show and not just tell them about some of the available indexes. Just as it is useful to discuss the differences between books and journals, it is also valuable to distinguish between scholarly journals and popular magazines. Foreign students may have difficulty understanding what a citation is and how to interpret it. Assigning a class exercise using a periodical index will help to identify students in need of further help. The librarian must explain the scope of an index and then show students how to find out which periodicals are available in their library and where they are located, otherwise, stu- 
dents may assume the library holds all titles indexed.

It is unrealistic to expect any student to retain all of what is covered in a class, especially students dealing with a foreign language. Ultimately, we want students to know where the card catalog and indexes are located so they can come back and work on their own. We want them to know where they can find help when they need it. Every class is followed by a short tour of the library so the students can make the connection between what they learned in class and the actual library. When time permits, the tour includes looking up a journal title in the periodical file and going to the stacks to locate it.

The teachers who have requested bibliographic instruction for foreign students often coordinate the class with a term paper assignment. This has proved to be a useful extension of the class, since afterwards, the team of teacher and librarian can continue to assist students as they begin their research, pointing out indexes or other sources that will help them.

Teaching foreign students is a timeconsuming job and one that requires a special sensitivity on the part of the librarian. Bibliographic instruction works well for those students whose teachers bring them to the library, but what about those international students who walk into the library on their own? Where, and how, do they begin? Are library personnel aware of the problems that foreign students must overcome?

\section{INCREASING STAFF SENSITIVITY}

There are many library staff who have neither the opportunity, the inclination, nor the position to teach foreign students; yet these same people may encounter more international students than the typical reference/instruction librarian. Terry Ann Mood discusses the importance of staff development, and suggests "providing reading lists of the foreign student experience in United States libraries to full time staff; a lecture series by foreign students at staff meetings; encouraging staff attendance at foreign student meetings; and offering the library as a site for their

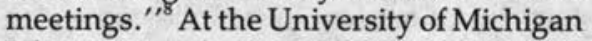
Libraries we chose to provide a more formal staff development program, due to the impact of a very large foreign student population.

\section{DESIGNING A STAFF DEVELOPMENT WORKSHOP}

A needs assessment was conducted to determine if other public service supervisors in the system felt that such a workshop was necessary, and if so, which members in their units would be interested in attending. An overwhelmingly positive response was received, and a four-hour workshop was planned. The goals were for the participants to "learn to differentiate between cultural and individual behavior patterns; heighten their sensitivity to problems facing foreign students; and learn to communicate more effectively with the foreign student population." The workshop was limited to twenty-five participants to facilitate discussion and small-group exercises. Participants were primarily from public service units (e.g., engineering library, graduate library circulation, and reference), and rank ranged from clerical to professional.

A videotape prepared by the University of Arizona Libraries was used to help sensitize workshop participants immediately to the importance of understanding the experiences of foreign students. ${ }^{10}$ The videotape is composed of three different segments: interlibrary loan procedures, bibliographic instruction techniques, and cross-cultural communications at the reference desk. After watching the interlibrary loan segment, which is primarily in Spanish, participants took a written quiz (also provided by the University of Arizona Libraries) on the correct procedures for interlibrary loan. This method succeeded in demonstrating to staff the plight of foreign students using American libraries and the difficulty of following instructions in another language. For example, even those with a working knowledge of Spanish were unable to understand completely the directions given on how to complete forms. A general discussion of 
the varied communication problems of international students was followed by an exercise in stereotyping.

\section{STEREOTYPES AND CULTURAL TRAITS}

Stereotypes can be a dangerous concept on which to build an exercise, but this part of the workshop turned out to be a useful lesson in cultural awareness. Stereotype has been defined by J. W. Vander Zanden as "a category that singles out an individual as sharing assumed characteristics on the basis of this group membership." Walter Lippman believes that people react to the stereotype of the object and not to the object itself. ${ }^{12}$ One objective of the workshop was for participants to realize that although everyone is a member of some culture, he or she is also an individual with a unique personality and problems. Some patrons may be difficult as individuals for which their cultural group is not to blame.

The University of Michigan has more than 2,000 foreign students. The largest cultural groups are from East Asia, India, the Middle East, and Southern Europe. ${ }^{13}$ The class was divided into small groups to represent each of the above cultures. In addition, a group representing the United States was included.

Using a modified version of a questionnaire designed by Dixon C. Johnson, a list of cultural and linguistic attributes was created prior to the workshop. ${ }^{14}$ Copies of the list were distributed, and the groups stereotyped their cultures. Many of the participants were initially uncomfortable in being asked to stereotype, but once negative feelings were confronted, the group was able to deal with them in an open manner. The results were tabulated on the board, and a final column was added, labeled "effective techniques for communicating." Many of the participants had lived in foreign countries, were born overseas, or were related to foreigners, and so discussion was lively. For example, the East Asian group selected the adjectives quiet, strong accent, restrained, stiff, formal, passive, and respectful as stereotypical attributes. Polite, kind, formal, serious, studious, friendly, courteous, and shows appreciation were used to describe them culturally. Communication strategies suggested for dealing with East Asian students were to speak slowly, avoid idioms, and use written handouts. Also, staff were encouraged to phrase questions in the least confusing manner, avoiding sentences like "You didn't use the card catalog, did you?"' Some students will respond to this positively, but actually mean, "Yes, I didn't."

Different cultures have different concepts of personal space. North Americans feel comfortable with a conversational distance of about five feet; Arabs, two feet. ${ }^{15}$ As a result, it is common for North American women to feel that Arabs are more interested in them as women than as professionals. This is not the case. Arabs communicate nonverbally through touch and eye contact much more than westerners. This can be disconcerting when a librarian is helping someone from the Middle East. Keep in mind that they are not leering and do not shy away from establishing eye contact while you respond to the reference query as usual. ${ }^{16} \mathrm{~A}$ librarian may want to treat an extreme situation as an opportunity to educate, calmly explaining that most Americans are uncomfortable by extended eye contact or touching.

The stereotype exercise proved valuable, leading participants to analyze behavior and distinguish cultural from individual patterns. The ability to assess objectively a cross-cultural situation will help these staff members in future interactions with foreign students. Neither the leaders nor the participants were experts in this area, but benefited from exchanging successful techniques and strategies.

The session also included discussion of high- and low-context cultures and libraries as a product of culture. A highcontext culture, such as that of the Middle East or China, has these characteristics: greater distinction between insiders and outsiders; polychronic time (many things happening at once); greater interdependency among people; and subtlety in discussion. United States culture, which is low context, is more open to outsiders, uses linear time, and promotes selfsufficiency. Learning is a process of imita- 
tion and rote memorization in highcontext cultures, whereas low-context cultures emphasize questioning and challenging authority. ${ }^{17}$

Another exercise was conducted to demonstrate how libraries reflect their cultural contexts. Attributes common to U.S. libraries, both public and academic, were compared with qualities common to libraries overseas. Curiously, people were slow to name characteristics of the libraries that they utilize on a daily basis. However, once begun, it became clear that as Americans we have high expectations of our libraries: free access, open stacks, borrowing privileges, computer access, interlibrary loan, professional help, and a place to stay warm in the winter and cool in the summer.

\section{STUDENTS USING LIBRARIES}

Institutions, regulations, and communication patterns reflect the particular culture in which they are developed. American students take it for granted that they may browse, look for their own books, and have instant access to a variety of resources. Foreign students often do not make these same assumptions. They may have used the library merely as a study hall, never asking for professional help. A foreign student in the United States not only has to learn a new language but also must learn an entirely new set of rules if he or she is to function properly in society. Every culture has its own subtleties and distinctions that often cannot be translated but must be learned through experience. Weston La Barre has pointed out that one must understand the context to interpret everyday customs correctly. ${ }^{18}$ Understanding this concept is a major step toward accepting those different from ourselves.

To close the workshop we viewed the "Cross-Cultural Communication" segment of the Arizona videotape. Discus- sion focused on scenes in which students, one foreign and one North American, ask to borrow a reference book overnight. Though the script was the same, nonverbal communication was very different in the two cases and was more powerful than the verbal exchange. The videotape prompted an exchange of ideas on how to handle similar situations productively.

Participants' evaluations showed the workshop was successful in broadening their understanding of the foreign student's perspective. This is only one of a number of approaches that could be used to help library staff interact better with foreign students. A workshop with foreign students describing their experiences firsthand would also help to raise consciousness. Mood suggests that by designating a special liaison for foreign students the library would demonstrate its willingness to respond to their needs. ${ }^{19} \mathrm{~A}$ program of awareness training, even if not an entire workshop, on handling the problems of foreigners in the library, could be designed for public service staff.

\section{SUMMARY}

Bibliographic instruction and staff development programs designed for foreign students not only sensitize personnel but also encourage cross-cultural understanding at a grass-roots level. As these students become a more visible part of the academic community, the library and its parent institution should take the initiative to meet their needs. Each library must assess its own situation; considering how many foreign students are on campus; what their impact may be on the library; what type of interaction takes place presently; and what future institutional and individual goals and objectives for working with international students are. Once these questions have been answered, one only needs the energy, enthusiasm, and desire to achieve the goals.

\section{REFERENCES}

1. Scott Jaschik, "Seeking to Compete in World Economy, States Back International Education," Chronicle of Higher Education, December 4, 1985, p.1, 18-19.

2. Ibid. 
3. Sally G. Wayman, "The International Student in the Academic Library," Journal of Academic Librarianship 9:336-41 (Jan. 1984).

4. Terry Ann Mood, "Foreign Students and the Academic Library," RQ 22:175-80 (Winter 1982).

5. Wayman, p.338-39.

6. International Handbook of Contemporary Developments in Librarianship, ed. Miles M. Jackson (Westport, Conn.: Greenwood, 1981).

7. Ibid., p.127.

8. Mood, p.178.

9. Mary Alice Ball and Molly Mahony, Staff Development Workshop Proposal (University of Michigan, March 25, 1985).

10. Susan Johnston, L. W. Greenfield, and Karen Williams, Préstamos Entre Bibliotecas (Univ. of Arizona: Video Productions, Media \& Industrial Services, c.1983).

11. J. W. Vander Zanden, American Minority Relations: The Sociology of Racial and Ethnic Groups (New York: Ronald, 1966).

12. Nelson R. Cauthen, I. E. Robinson, and H. H. Kraus, "Stereotypes: A Review of the Literature," Journal of Social Psychology 84:104 (June 1971).

13. 1984 Foreign Student Statistics, Report prepared by University of Michigan International Center (Univ. of Michigan, Ann Arbor, Nov. 1984).

14. Dixon C. Johnson, "Ourselves and Others: Comparative Stereotypes," International Educational and Cultural Exchange 9:24-28 (Fall/Winter 1973-74).

15. Edward T. Hall, "Learning the Arab's Silent Language," Psychology Today 13:48 (Aug. 1979).

16. Ibid., p.48.

17. Edward T. Hall, Beyond Culture (Garden City, N.J.: Anchor Bks., c.1976).

18. Ibid., p.113.

19. Mood, p.179. 


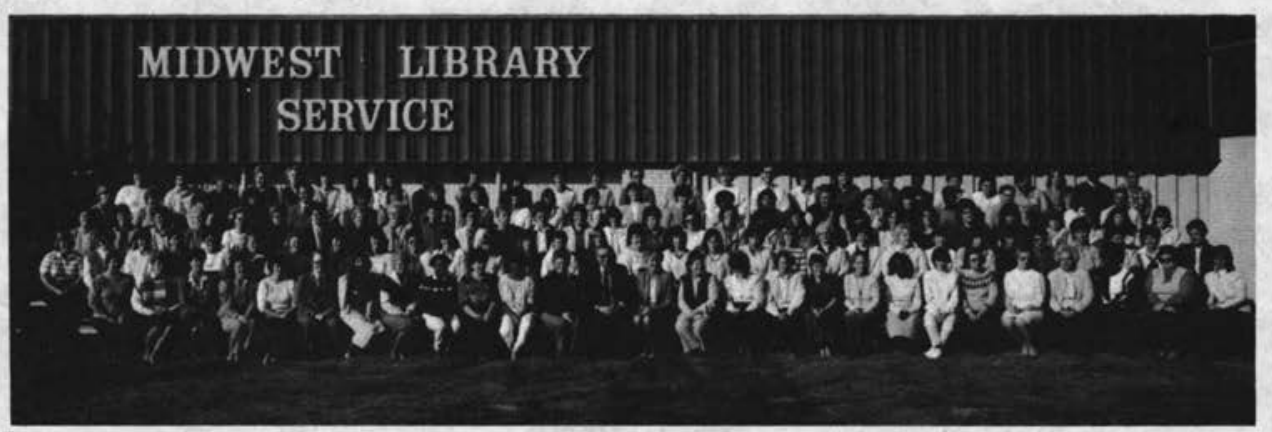

\section{MLS-160 People Dedicated to Providing Service to Libraries}

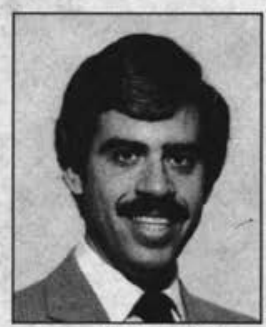

Jay Askuvich General Sales Manager

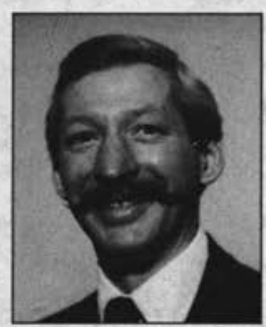

Kevin Coyle Midwest

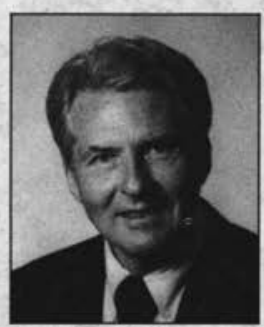

Carl Dorr

Southeast

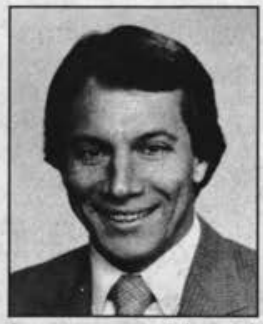

Lawrence Nagel West

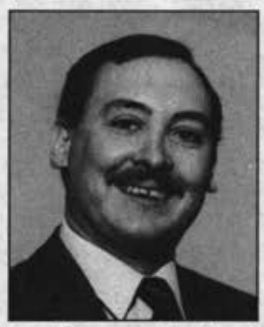

Forrest Link Northeast

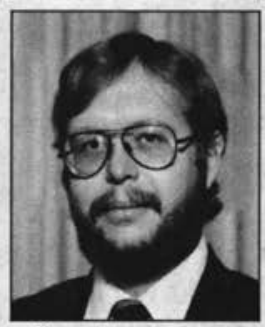

Kim Anderson Mountain Plains

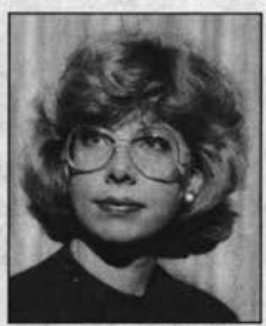

Lorraine Best Canada

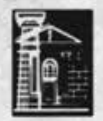

\section{Midwest Library Service}

11443 St. Charles Rock Road Bridgeton, MO 63044, USA

Call toll-free 1-800-325-8833 Missouri librarians call toll-free 1-800-392-5024 Canadian librarians call toll-free 1-800-527-1659 


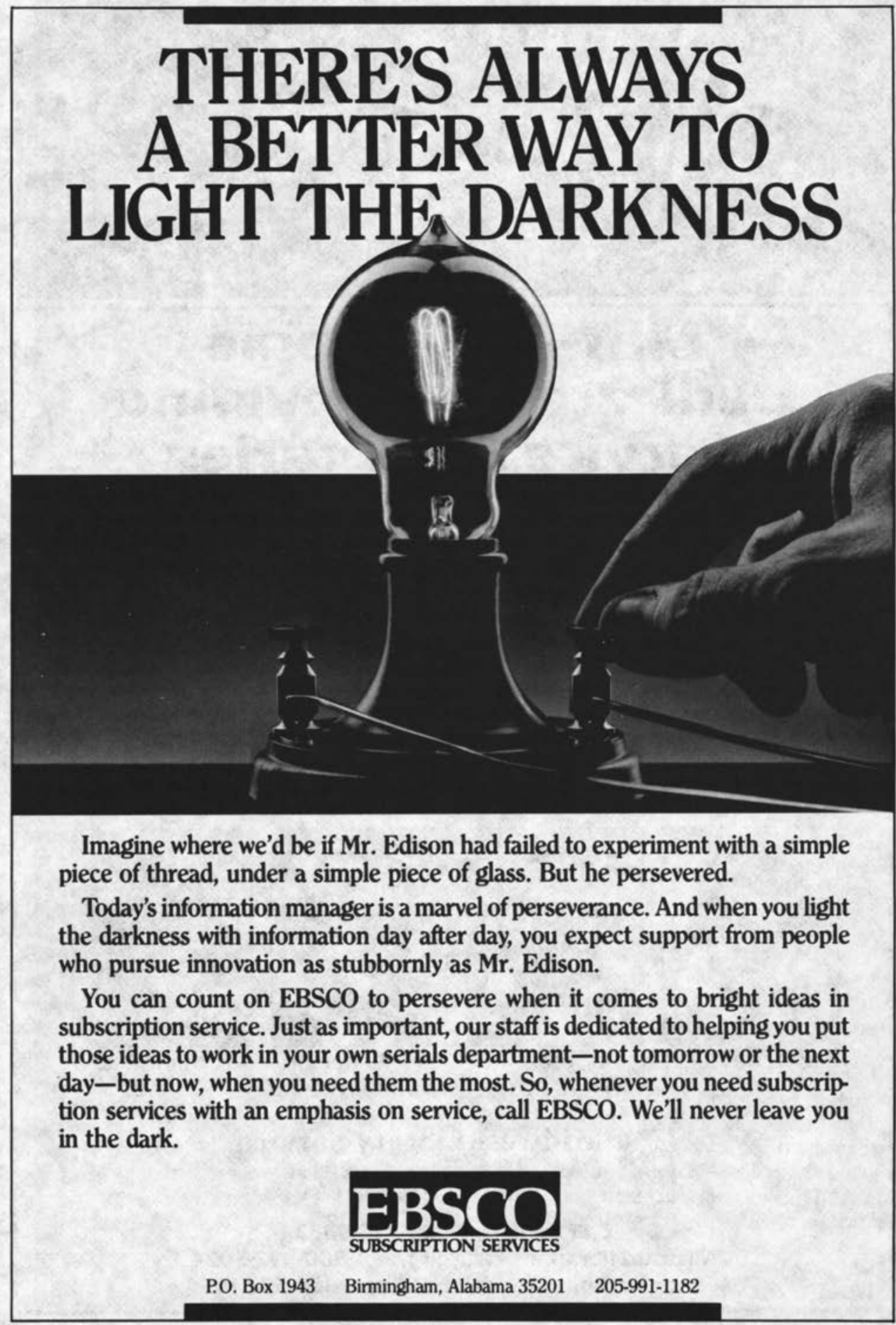

